\title{
Yield Enhancement Strategies for Enhancement of Indole Alkaloids in Hairy Root Cultures of Catharanthus Roseus
}

\author{
D. Thakore, A. K. Srivastava, and A. K. Sinha
}

\begin{abstract}
Abstarct-Late exponential phase of hairy root cultures of Catharanthus roseus cultivated in a statistically optimized medium were treated with permeabilizing agents (DMSO, Triton X-100, n-hexadecane and Tween 80) to establish the effect of their concentrations and exposure time on the biomass and major alkaloid(ajmalicine) yield \& productivity. The permeabilizing agents TritonX-100(0.1\% v/v) and nhexadecane $(2 \% \mathrm{v} / \mathrm{v})$ led to $98 \%$ increase in the specific yield of ajmalicine in the roots. Statistical techniques were used to determine the significance of various treatments and their response on the yield of the secondary metabolite. Both DMSO and Triton X-100 were found to be useful in effluxing ajmalicine into the medium resulting in a 12 fold and 16 fold increase respectively. The viability assay revealed the tolerance of the roots to all permeabilizing agents but tween 80 .It can be concluded from the studies that permeabilizing factors were highly instrumental in enhancing the biomass and alkaloid concentrations and rates during the propagation of hairy root cultivation of Catharanthus roseus. Such a protocol of application of non lethal permeabilizing agents to leach out the key plant secondary metabolites can be extended to mass scale hairy root cultivation.
\end{abstract}

Index Terms - Catharanthus roseus, hairy root cultivation , permeabilization.

\section{INTRODUCTION}

Catharanthus roseus has been a source of wide variety of biologically active compounds. Ajmalicine is one such important monterpene indole alkaloid obtained from this plant, the production of which has been used as a model system for improvement in the bioprocess of several plant metabolites .The main bottleneck in the commercialization of the hairy root cultivation process is the low yield as well as the intracellular localization of the commercially important compounds [1]. Ajmalicine is stored in the vacuoles where by the action of the peroxidases it gets converted to serpentine thus making the continuous leaching out of the product all the more important. Permeabilizing agents are those chemical compounds (solvents) which, under non-inhibitory concentration levels, have the ability to reversibly increase the pore size of the cell wall as well as the vacuoles in order to leach out the metabolites so that the cell grows normally again for better mass transfer with respect to substrate and the product, leading to increased

Manuscript received March 10, 2013; revised May 12, 2013.

D. Thakore and A. K. Srivastava are with the Department of Biochemical Engineering and Biotechnology, Indian Institute of Technology Delhi, Hauz Khas, New Delhi-110016, India (e-mail: dharathakore@gmail.com and ashokiitd@hotmail.com )

K. Sinha is with National Institute of Plant Genome Research, New Delhi, India (e-mail :alok_sinha@nipgr.res.in) biomass and secondary product formation (and thereby increasing the overall productivity) by plant cells. This selective leaching of the product in the broth will not only facilitate the down- stream processing but also revive the cellular metabolism which otherwise get reduced due to accumulation of metabolites in the vacuoles. The effect of the permeabilizing agents is species specific and no generalized theories are therefore available to interpret their mechanism of action. Therefore it becomes important to select the right permeabilizing agent and optimize its dosage and time for better response from the system. In the present study several permeabilizing agents have been tested for hairy roots of $C$. roseus to create an environment for better yield of the alkaloids without sacrificing the viability. Biocompatibility is a major concern when biological and organic phases are brought in contact apart from the high product release capacity, chemical and thermal stability, non degradability, low emulsion forming tendency and low cost [2]. The efficacy and cost factors have led to predominant use of organic solvents as agents for permeabilization [3]. The compounds used in this investigation were selected on the basis of $\log \mathrm{P}$ value. The toxicity is correlated inversely with $\log \mathrm{P}$, which is defined as the common logarithm of the partition coefficient $(\mathrm{P})$ of the organic solvent between $\mathrm{n}$ octanol and water $(\log \mathrm{P}>5$ are found to be nontoxic) [4].The experiments were conducted to analyze the effect of a single factor at a time on the ajmalicine production and release rather than a synergistic response due to a possible detrimental effect of the solvent combination.

\section{MATERIALS AND METHODS}

\section{A. Hairy Root Culture}

The cultures were maintained by transferring $0.5 \mathrm{~g}$ root tips into $40 \mathrm{~mL}$ liquid $1 / 2 \mathrm{~B} 5$ medium (half dilution of the standard B5)containing 3\% sucrose every two weeks. .Cultures were incubated at $250 \mathrm{C}$ with $16 / 8$ light/dark illumination conditions. Experiments were conducted in statistically optimized $\mathrm{B} 5 / 2$ medium of the following composition:2.75 g/l , nitrate: 37.5 $\mathrm{mg} / \mathrm{l}$,Phosphate along with Gamborg B5/2 Major salts + $\mathrm{B} 5 / 2$ Minor salts+B5 vitamins $+16 \mathrm{~g} / 1$ sucrose [5].The $\mathrm{pH}$ of the medium was adjusted to 5.8 before autoclaving. All the further experiments were conducted in the modified medium.

\section{B. Analysis of Alkaloids}

The fresh weight was analyzed by blotting dry the harvested roots immediately after sampling. For dry weight measurement the hairy roots were incubated at $35{ }^{\circ} \mathrm{C}$ till a constant dry weight (DW) was obtained. Dried powdered 
root samples were extracted with methanol thrice and the extract was evaporated to $1 / 3$ rd volume and acidified with $3 \% \mathrm{HCl}$.To this solution, equal volume of ethyl acetate was added and phase separation was allowed to take place. The lower aqueous solution was collected and the $\mathrm{pH}$ was increased to 8.5 by the addition of liquor ammonia. This was then extracted with chloroform and the lower chloroform fraction was evaporated to dryness. The final sample was prepared in methanol.

The extract was quantified by High-performance liquid chromatography (Agilent technologies, USA) using a reversed phase C18 analytical column $(4.6 \mathrm{~mm} \times 150 \mathrm{~mm}$ $5 \mu \mathrm{m}$, Agilent Technologies 1200 series, USA ).

A photo diode array detector (DAD) was used for recording the absorption spectra (at 220nm) of the compounds using a linear gradient elution of acetonitrile and phosphate buffer as described elsewhere [6].

\section{Test for Viability}

Tetrazoliumtrichloride (TTC) is reduced to a pink Triphenylformazan complex by live root tissues with a peak absorbance at $520 \mathrm{~nm}$. This biochemical assay depends on the activity of the mitochondrial respiratory chain in living tissues which reduces tetrazolium salts to formazan products. Two hundred mg of fresh weight of hairy roots was cut into 1 to $2 \mathrm{~mm}$ long fragments and put into $10 \mathrm{ml}$ vials containing $6 \mathrm{ml}$ TTC-solution $(0.6 \% \mathrm{w} / \mathrm{v}, \quad 2,3,5$ triphenyltetrazoliumchloride in $0.06 \mathrm{M} \mathrm{Na} 2 \mathrm{HPO} 4-\mathrm{KH} 2 \mathrm{PO} 4$ and $0.05 \% \mathrm{v} / \mathrm{v}$, Tween 20). The sample was incubated for $20 \mathrm{~h}$ at $30 \mathrm{OC}$ in dark. The formazan product was extracted for 15 minutes in $95 \%$ (v/v) Ethanol (up to 60 0C) and the light absorption was measured at $520 \mathrm{~nm}$ by spectrophotometer. The viability of the test samples was expressed as relative viability (as percentage with respect to the control samples) assuming control samples as $100 \%$ viable [7].

\section{Screening Experiments}

Since different permeabilizing agents can trigger the biosynthetic pathway in a different manner several compounds were screened to establish their suitability (Table I) : DMSO $(0.5 \%, 1 \%$ and $2 \% \mathrm{v} / \mathrm{v})$ (Qualigens, India ) Tween $80(0.01 \%, 0.5 \% 1 \%$ v/v)Triton X 10( $0.01 \%$, $0.5 \%$ and $1 \%$ v/v)and n- hexadecane(1\%,2 \%and $4 \%$ $\mathrm{v} / \mathrm{v})($ Spectrochem, India) were added after aseptic filter sterilization through $0.22 \mu \mathrm{m}$ syringe (Millipore) filters. Complete growth and production profile indicated that the growth and synthesis were uncoupled (data not shown) and product is primarily accumulated in later (non growth) phase. Based on the above observations all the experiments were carried out with 15 days old root cultures with addition of the permeabilizing agents on day 26 (late exponential phase) to allow for adequate biomass accumulation by avoiding chemical stress in the lag or early exponential phase and allow the activation of the enzyme machinery as ajmalicine production begins in the stationery phase. Flasks were harvested on day 30. Equal amount of water was added to the control cultures.

\section{E. Statistical Analysis}

The variations between the treatments were analyzed by running the data of the different experiments through one way ANOVA using Design expert version 5.0.9. ANOVA values between the permeabilizing agents were calculated and null hypothesis was applied. The student t-test was used for the comparison of mean (after a significant overall $\mathrm{F}$ test was observed in ANOVA) but more importantly to obtain a $\mathrm{P}$ value (Table II).The results were considered as statistically significant for values of $P \leq 0.05$. The data was assumed to be normally distributed in the entire range.

TABLE I : EFFECT OF PERMEABILIZATION

\begin{tabular}{|c|c|c|c|c|c|}
\hline $\begin{array}{c}\text { Permeabilizing } \\
\text { Agent }\end{array}$ & Concentration & Dry weight (DW)g/l & $\begin{array}{c}\text { Ajmalicine } \\
\text { mg/gDW(root) }\end{array}$ & $\begin{array}{l}\text { Ajmalicine mg/l } \\
\text { (medium) }\end{array}$ & Viability\% \\
\hline \multirow[t]{3}{*}{ DMSO } & $0.5 \% \mathrm{v} / \mathrm{v}$ & $4.368 \pm 1.29$ & $3.22 \pm 0.32$ & 13.45 & 89 \\
\hline & $1 \% \mathrm{v} / \mathrm{v}$ & $3.6 \pm 0.543$ & $4.08 \pm 0.419$ & 13.987 & 80 \\
\hline & $2 \% \mathrm{v} / \mathrm{v}$ & $3.42 \pm 0.26$ & $4.89 \pm 0.663$ & 15.34 & 78.5 \\
\hline \multirow[t]{3}{*}{ Tween 80} & $0.01 \% \mathrm{v} / \mathrm{v}$ & $3.99 \pm 0.359$ & $1.58 \pm 0.183$ & 0.245 & 56.9 \\
\hline & $0.5 \% \mathrm{v} / \mathrm{v}$ & $4.1 \pm 0.22$ & $2.44 \pm 0.494$ & 4.33 & 54 \\
\hline & $1 \% \mathrm{v} / \mathrm{v}$ & $3.61 \pm 0.149$ & $4.015 \pm 0.813$ & 12.32 & 48 \\
\hline \multirow[t]{3}{*}{ Triton X-100 } & $0.01 \% \mathrm{v} / \mathrm{v}$ & $3.89 \pm 0.193$ & $9.5 \pm 0.659$ & 22.54 & 83 \\
\hline & $0.5 \% \mathrm{v} / \mathrm{v}$ & $3.43 \pm 0.26$ & $9.86 \pm 0.714$ & 20.22 & 82.43 \\
\hline & $1 \% \mathrm{v} / \mathrm{v}$ & $3.07 \pm 0.417$ & $5.07 \pm 0.579$ & 18.675 & 65 \\
\hline \multirow[t]{3}{*}{$\mathrm{n}$ hexadecane } & $1 \% \mathrm{v} / \mathrm{v}$ & $3.43 \pm 0.477$ & $7.75 \pm 1.07$ & 3.665 & 88 \\
\hline & $2 \% \mathrm{v} / \mathrm{v}$ & $3.525 \pm 0.95$ & $9.83 \pm 1.98$ & 10.18 & 83.62 \\
\hline & $4 \% \mathrm{v} / \mathrm{v}$ & $3.15 \pm 0.51$ & $0.59 \pm 0.04$ & - & 44 \\
\hline control & & $5.125 \pm 0.17$ & 4.97 & 1.33 & 100 \\
\hline
\end{tabular}

\section{RESULTS AND DISCUSSIONS}

\section{A. Dosage Studies}

Addition of DMSO allowed for a significant amount of alkaloid release at all concentrations with the maximum at $2 \% \mathrm{v} / \mathrm{v}(15.34 \mathrm{mg} / \mathrm{l}$, a 12 fold increase, $\mathrm{F}=444.64$, $\mathrm{P}>0.0022)$ Though the ajmalicine accumulation increased with increasing concentration of DMSO it was lower than 
the control even with the supplementation of the highest concentration $(2 \mathrm{v} / \mathrm{v} \%)$. The biomass exhibited a slight decrease as compared to control at all concentrations of DMSO. A similar observation has been reported earlier wherein the increase in DMSO treatment from 0.5 to $2 \%$ in Catharanthus roseus hairy roots decreased the biomass to $6.3 \mathrm{~g} / \mathrm{l}$ as compared to $7.9 \mathrm{~g} / \mathrm{l}$ in control [8]. Triton $\mathrm{X}-100$ is a commonly used surfactant in the food industry [9] and is also extensively used as a permeabilizing agent for several plant cell systems [10]. In the present study also efficient efflux of ajmalicine was observed $(22.5 \mathrm{mg} / \mathrm{l}$, a 16 fold increase) compared to control cultures at the lowest concentration of Triton X-100 $(0.01 \% \quad \mathrm{v} / \mathrm{v})(\mathrm{F}=439.29$, $\mathrm{P}>0.0023)$ which is of particular importance from the economic point of view especially in large scale reactors. Ajmalicine synthesis was simulated at all concentrations studied with a $97 \%$ higher content. $(9.86 \pm 0.714 \mathrm{mg} / \mathrm{gDW})$ with $0.5 \%$ v/v Triton -X $100(\mathrm{~F}=201.04, \mathrm{P}>0.005)$. Addition of $n$-hexadecane $(\log \mathrm{P}$ value $=8.8)$ led to an increase in ajmalicine release and accumulation with maximum of $9.83 \pm 1.98 \mathrm{mg} / \mathrm{gDW}$ at $2 \% \mathrm{v} / \mathrm{v}(\mathrm{F}=267.8, \mathrm{P}>0.0037)$ as compared to control. Further increase in concentration decreased the ajmalicine accumulation $(\mathrm{F}=194.5, \mathrm{P}>0.005)$. A slight reduction in dry weight was observed at all concentrations. The advantage in $n$-hexadecane treatment lies in the fact that it acts as both a permeabilizing agent and oxygen carrier [11] and [12]. Tween 80 (Polyoxy ethylene sorbilane monolaurate) widely used in microbial and animal technologies failed to over induce the ajmalicine accumulation in the roots as well in the medium at all tested concentrations However, at $1 \% \mathrm{v} / \mathrm{v}$ the ajmalicine content showed a slight increase which might be due to the increased stress induced on the roots that might have led to cell lysis as the viability was seen to drop to $48 \%$. This is contradictory to the results reported for Glycyrrhiza uralensis hairy roots [13] showing that the effect of the permeabilizing agents cannot be generalized. ANOVA was started with the F-test, the significance level associated with which was $\mathrm{P} \leq 0.05$. The F-test was found to be significant for all treatments which indicates the rejection of the nullhypothesis ,that the independent variable has no linear effect on the dependent variable. A detailed statistical evidence of the significant difference between the population means for ajmalicine accumulation as well as release. was achieved by student t- test (see Table II).

\section{B. Effect on Cell Viability}

The cell viability is of utmost importance when the cultures are exposed to different permeabilizing agents to allow for recycling of the biomass and medium. The viability was observed to vary from $89 \%$ to $78.5 \%$ as the DMSO concentration was increased from $0.5 \% \mathrm{v} / \mathrm{v}$ to $2 \%$ v/v. Dimethylsulfoxide (DMSO) has been used for the reversible permeabilization of immobilized cells of Catharanthus roseus[14] .Previous reports suggest the tolerance of Catharanthus roseus cells towards DMSO[15]. Triton X-100 caused a significant loss in viability only at the highest concentration $(1 \% \mathrm{v} / \mathrm{v})$. Hairy roots were found to be tolerant to hexadecane treatment except at $4 \% \mathrm{v} / \mathrm{v}$ as opposed to tween 80 which led to a loss of viability at all concentrations.
TABLE II: T-TEST FOR COMPOSITION OF MEAN

\begin{tabular}{|c|c|c|}
\hline Treatment & $\begin{array}{l}t \text { for } \mathrm{Ho}_{0} \\
\text { coeff }=0\end{array}$ & Prob $>t$ \\
\hline \multicolumn{3}{|c|}{ Ajmalicine accumulation in the roots } \\
\hline $\begin{array}{l}\text { Hexadecane vs } \\
\text { DMSO }\end{array}$ & 38.29 & $\mathrm{P}<0.0001 * * *$ \\
\hline $\begin{array}{l}\text { Hexadecane vs } \\
\text { Tween } 80\end{array}$ & 44.84 & $\mathrm{P}<0.0001 * * *$ \\
\hline $\begin{array}{l}\text { Hexadecane vs } \\
\text { Triton X } 100\end{array}$ & 3.05 & $\mathrm{P}<0.038^{*}$ \\
\hline $\begin{array}{l}\text { Triton X } 100 \text { vs } \\
\text { Tween } 80\end{array}$ & 41.79 & $\mathrm{P}<0.0001 * * *$ \\
\hline $\begin{array}{l}\text { Triton X } 100 \text { vs } \\
\text { DMSO }\end{array}$ & 35.24 & $\mathrm{P}<0.0001 * * *$ \\
\hline $\begin{array}{l}\text { DMSO vs } \\
\text { Tween } 80\end{array}$ & 6.55 & $\mathrm{P}<0.0028 * *$ \\
\hline \multicolumn{3}{|c|}{ Ajmalicine accumulation in the medium } \\
\hline $\begin{array}{l}\text { Hexadecane vs } \\
\text { DMSO }\end{array}$ & 38.29 & $\mathrm{P}<0.0001 * * *$ \\
\hline $\begin{array}{l}\text { Hexadecane vs } \\
\text { Tween } 80\end{array}$ & 44.84 & $\mathrm{P}<0.0001 * * *$ \\
\hline $\begin{array}{l}\text { Hexadecane vs } \\
\text { Triton X } 100\end{array}$ & 3.05 & $\mathrm{P}<0.0001 * * *$ \\
\hline $\begin{array}{l}\text { Triton X } 100 \text { vs } \\
\text { Tween } 80\end{array}$ & 41.79 & $\mathrm{P}<0.0018^{* *}$ \\
\hline $\begin{array}{l}\text { Triton X } 100 \text { vs } \\
\text { DMSO }\end{array}$ & 35.24 & $\mathrm{P}<0.0001 * * *$ \\
\hline $\begin{array}{l}\text { DMSO vs } \\
\text { Tween } 80\end{array}$ & 6.55 & $\mathrm{P}<0.0001 * * *$ \\
\hline
\end{tabular}

* Magnitude of Difference . For $\mathrm{P}>0.1$ the difference is completely insignificant, $\mathrm{P}<0.05$ significant, $\mathrm{P} \leq 0.0001$ highly significant

\section{CONCLUSION}

All the permeabilizing agents used for the investigation exhibited different trends with respect to production ranging from $0.59 \pm 0.04 \mathrm{mg} / \mathrm{gDW}$ to $9.86 \pm 0.714 \mathrm{mg} / \mathrm{gDW}$. The efficient efflux of ajmalicine by permeabilizing agents $n$ hexadecane, Triton X -100 and DMSO as compared to control was confirmed in the present study. The above results suggest that a cycle of growth phase followed by an optimal production and permeabilization procedure can be applied repeatedly. This technique in future may find an application in the downstream processing not only by leaching out water soluble vacuolar secondary metabolites like ajmalicine but also preventing the feed back inhibition by removal of the end products [16], [17] of the pathway particularly in large scale systems [18], [19] thus facilitating a continuous product recovery and enhanced culture growth and metabolic activities of rather slow growing plant hairy roots.

\section{REFERENCES}

[1] W. Zhang, C. Curtin, and C. Franco, "Towards manipulation of postbiosynthetic events in secondary metabolism of plant cell cultures," Enzyme Microb Technol, vol. 30, issue 6, pp. 688-96, May 2012.

[2] R. León, P. Fernandes, H. Pinheiro and J. Cabral, "Whole-Cell Biocatalysis in Organic Media," Enz Microb Technol, vol. 23, pp483-500, Nov 1998.

[3] F. Zhanga, L. H. Chengb, X. H. Xub, L. Zhanga, and H. L. Chen, "Screening of biocompatible organic solvents for enhancement of lipid milking from Nannochloropsis sp.," Process Biochemistry, vol. 46, pp. 1934-1941, October 2011. 
[4] R. A. Abusham, "Isolation and Charecterization of Thermostable Organic Solvent Tolerant Protease from Bacillus subtilis isolate rand," M. S. Thesis, Biotechnology and Biomolecular Sciences, Universiti Putra Malaysia, Malaysia, 2009.

[5] D. Thakore, A. K. Srivastava, and A. Sinha, "Enhanced Production of Antihypertensive Drug Ajmalicine in Transformed Hairy Root Culture of Catharanthus Roseus by Application of Stress Factors in Statistically Optimized Medium," in Chemistry of Phytopotentials: Health, Energy and Environmental Perspectives, L. D. Khemani, M M. Srivastava, Srivastava, Shalini eds., Springer Berlin Heidelberg India, 2012, pp. 39-42.

[6] D. Singh, S. Pandey, S. K. Rai Srivastava, R. Mishra, and S. Kumar, "Simultaneous quantification of some pharmaceutical Catharanthus roseus leaf and root terpenoid indole alkaloids and their precursors in single runs by reversed phase liquid chromatography," J. of AOAC International, vol. 87, pp. 1287-96, Dec 2004.

[7] S. B. Brunner and L. Walthert, "Fine root chemistry, starch concentration, and 'vitality' of subalpine conifer forests in relation to soil pH," Ecol. Manage, vol. 165, pp. 75-84, July 2002.

[8] S. J. Sim, H. N. Chang, J. R. Liu, and K. H. Jung, "Production and secretion of indole alkaloids in hairy root cultures of Catharanthus roseus: Effects of in situ adsorption, fungal elicitation and permeabilization," J Ferm Bio., vol. 78, issue 3, pp. 229-234, June 1998.

[9] R. Thimmaraju, N. Bhagyalakshmi, M. S. Narayan, and G. A. Ravishankar, "Food-Grade Chemical and Biological Agents Permeabilize Red Beet Hairy Roots, Assisting the Release of Betalaines," Biotechnol. Prog, vol. 19, pp. 1274-1283, May 2003.

[10] M. Arenas-Ocampo, L. Alamilla-Beltrán, P. Vanegas-Espinoza, B. Camacho-Díaz, R. Campos-Mendiola, G. Gutiérrez-López, and 'A. Jiménez-Aparicio, "Fractal morphology of Beta vulgaris L. cell suspension culture permeabilized with Triton X-100®," International Agrophysics, vol. 26, issue 1, pp. 1-6, March 2012.

[11] S. Chattopadhyay, S. Farkya, A. K. Srivastava, and V. S. Bisaria "Bioprocess Considerations for Production of Secondary Metabolites by Plant Cell Suspension Cultures," Biotechnol. Bioprocess Eng, vol. 7, pp. 138-149, 2002.

[12] Y. S. Liu and J. W. Wu, "Use of n-hexadecane as an oxygen vector to improve Phaffia rhodozyma growth and carotenoid production in shake-flask cultures," J Appl Microbiol , vol. 101, no. 5, pp. 1033-8, Nov 2006.

[13] H. C. Zhang, J. M. Liu, H. M. Chen, C. C. Gao, H. Y. Lu, H. Zhou, Y $\mathrm{Li}$, and S. L. Gao, "Up-Regulation of Licochalcone A Biosynthesis and Secretion by Tween 80 in Hairy Root Cultures of Glycyrrhiza uralensis," Mol Biotechnol, vol. 47, pp. 50-56, July 2011.

[14] P. Brodelius and K. Nilsson, "Permeabilization of Immobilized Plant Cells, Resulting in Release of Intracellularly Stored Products with Preserved Cell Viability," Eur J Appl Microbiol Biotechnol, vol. 17 pp. 275-280, 1983 .

[15] P. E. Brodelius, "Permeabilization of plant cells for release of intracellularly stored products: Viability studies,"Appl. Microbiol. Biotechnol. vol. 27, pp. 561-566, 1988.

[16] S. Chandra and R. Chandra, "Engineering secondary metabolite production in hairy roots," Phytochem rev., vol. 10, pp. 375-391, May 2011.

[17] L. Chiang and M. A. Abdullah, "Enhanced anthraquinones production from adsorbent-treated Morinda elliptica cell suspension cultures in production medium strategy," Process Biochem, vol. 42, pp. 757-763, May 2007.
[18] G. Prakash and A. K. Srivastava, "Integrated yield and productivity enhancement strategy for biotechnological production of Azadirachtin by suspension culture of Azadirachta indica," Asia-Pacific Jrnl of Chem. Eng, vol. 6, pp. 129-137, July 2011.

[19] S. Smita and A. K. Srivastava, "Azadirachtin production by hairy root cultivation of Azadirachta indica in a modified stirred tank reactor," Bioprocess \& Biosystems Engineering, vol. 35, issue 9, pp. 1549-53, May 2012.

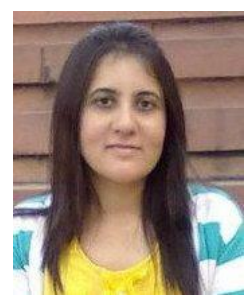

Dhara Thakore is a BTech in Chemical Engineering and is currently pursuing $\mathrm{PhD}$ in the department of Biochemical Engineering and Biotechnology at Indian Institute of Technology Delhi.

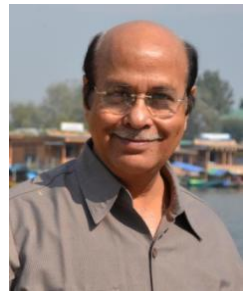

Ashok Kumar Srivastava received Ph.D. degree from the McGill University, Montreal (Quebec) in $1990 \mathrm{He}$ has extensive Industrial - Research and Teaching experience in the area of Biochemical Engineering and Biotechnology. He has worked for about a year in the Sorbose fermentation plant of M/S Jayant Vitamins Limited, Ratlam. He had worked in the Biochemical Engineering Group of National Chemical Laboratory, Pune for two years. He had served as Lecturer in the Biochemical Engineering and Food Technology Department of H.B. Technological Institute for ten years before joining IIT Delhi in 1991. He has received several awards and scholarships, important among them are first prizes for securing 1st position in B.Sc. Biochemical Engineering and M.Tech. Biochemical Engineering, National Overseas Scholarship award of MHRD New Delhi for Ph.D. studies (1985-1990), UNESCO fellowship award (6 months) for advanced studies in Biochemical Engineering at Biochemical Engineering Group, Delft University, The Netherlands, "Biotechnology Overseas Associate ship" 3 month at Institut fur Technische Chemie, Hannover, Germany), "Biotechnology Overseas Associate ship" (3 month at Massey University, New Zealand). He is the life member of "Indian Institute of Chemical Engineers" and "Biotechnology Research Society of India". He is in the editorial board of Process Biochemistry and Journal of Food Science and Technology

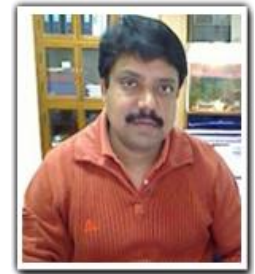

Alok Sinha received his Ph.D degree from National Botanical Research Institute Lucknow and Postdoctoral degree from University of Regensburg (AvH fellow) and University of Wuerzburg Germany. is interested in understanding the complexity of signals being transduced through mitogen activated protein kinase (MAPK) cascade in rice. 